\title{
Designing and revising a cognitive behavioral group intervention for psychological distress among female university students
}

\author{
Johanna Bernhardsdottir*1,2, Marga Thome ${ }^{1}$, Ingela Skärsäter ${ }^{3,4}$, Jane Dimmitt Champion ${ }^{5}$ \\ ${ }^{1}$ University of Iceland, Faculty of Nursing, Reykjavik, Iceland \\ ${ }^{2}$ University Hospital of Iceland, Landspitalinn, Iceland \\ ${ }^{3}$ Halmstad University, Halmstad, Sweden \\ ${ }^{4}$ Sahlgrenska Academy, Gothenburg, Sweden \\ ${ }^{5}$ University of Texas at Austin, Austin, Texas, United States
}

Received: July 31, 2017

DOI: $10.5430 /$ jnep.v8n3p64
Accepted: October 26, 2017

Online Published: November 10, 2017

\begin{abstract}
Background: Psychological distress in the form of depression and/or anxiety has been found to be common among university students, especially in females. Roughly one in five of Icelandic female university students exhibit elevated psychological distress, yet less than $30 \%$ of them do receive professional mental health care. To ameliorate the psychological distress a cognitive behavioral group therapy was designed to target the distress. The purpose of this paper is to describe the main steps in designing the respective intervention and the revisions made by the expert panel based on the validation of the preliminary intervention and the experience of the advanced practice psychiatric nurses therapists.

Methods: The intervention design took place in four phases. Initially psychological distress was defined, secondly a literature review was conducted to see if there were effective interventions available to solve the problem. Thirdly the drafting of the intervention took place based on theory and evidence and finally the intervention was validated with quantitative and qualitative methods. The intervention was provided by two advanced practice psychiatric nurses in 4 sessions in groups of 5 to 8 females. An expert panel of 6 psychiatric nurses was formed to guide the intervention design, the delivery of the intervention and intervention validation.

Results: The quantitative and qualitative validation of the preliminary intervention showed that psychological distress decreased and was acceptable to participants.

Conclusions: The validation of the preliminary intervention provided the expert group with rationale for modifying the content and structure of the intervention in nine categories.
\end{abstract}

Key Words: Advanced practice nurses, Cognitive behavioral group therapy, Females, Intervention design, Psychological distress, Students

\section{INTRODUCTION}

During university studies, students have been found to be prone to heightened psychological distress, especially fe- males and younger students. ${ }^{[1-5]}$ An Icelandic cross-sectional study found that roughly one in five Icelandic university female students have elevated levels of psychological distress.

*Correspondence: Johanna Bernhardsdottir; Email: johannab@hi.is; Address: Faculty of Nursing, University of Iceland, Reykjavik, Iceland. 
However, roughly $70 \%$ of the distressed Icelandic females' students do not receive any professional mental health care, a finding that is in line with other international findings. ${ }^{[6,7]}$ The main barriers to help-seeking, among the Icelandic university female students, were lack of time, money and not knowing where to seek help. ${ }^{[6]}$

Based on this high prevalence of psychological distress and the lack of mental health care for Icelandic female university students it was decided to design, validate and revise an intervention for this group to be delivered by advanced practice psychiatric nurses (APPN's). ${ }^{[8]}$ The framework by van Meijel, Gamel, van Swieten-Duijfjes and Grypdonck ${ }^{[9]}$ was chosen as a reference to systematically guide and describe this process. The initial step of intervention design according to this framework is to define the target group and operationalize the problem to be addressed. Secondly, a literature review is to be conducted to acquire the available evidence as it should be known beforehand if there are effective interventions available to solve the particular problem. The nature of clients' problems and service needs may also require assessment. The third step involves the drafting of the intervention based on theory and evidence. The intervention is then validated preferably with quantitative and qualitative methods. ${ }^{[9]}$

The phases of this current intervention design and rationale for revisions of the intervention based on the validation of the preliminary intervention will be described and discussed in this paper. The results of the quantitative and qualitative validation of the intervention have been reported elsewhere. ${ }^{[8,10]}$

\section{THE PROBLEM}

Psychological distress is an unpleasant subjective state which may encompass symptoms of depression and/or anxiety. Psychological distress is experienced on different levels of severity and may fluctuate within the same individual. Psychological distress is not a mental disorder but, especially depressive symptoms have been found to decrease quality of life, daily functioning and to increase the risk of full-blown disorders among those affected. ${ }^{[11,12]}$

Psychological distress among university students has frequently been associated with stress, which is also common among university students and more so for females than males. ${ }^{[13-16]}$ Students have been found to be mostly worried about how they achieve in their academic studies, the stress of being successful in their studies and future plans post education. Further, psychological distress has been related to financial concerns and interpersonal relationships among university students. ${ }^{[13,17-19]}$ It is also important to note that psychological distress, especially symptoms of depression, have been associated with lower academic achievement among university students and adverse health habits, such as poor eating and sleeping habits, smoking and problem drinking and acute infectious illnesses in students. ${ }^{[20-26]}$ Taken together, these findings indicate the importance of assessing and addressing psychological distress related to stress in students with effective interventions and to reduce maladaptive coping behavior. ${ }^{[4]}$

\section{Literature REVIEW}

According to van Meijel et al. ${ }^{[9]}$ an essential element in designing an intervention is the comprehension of the problem to be addressed by the intervention, the nature of service needs of clients and whether other interventions are available. The literature has revealed that cognitive behavioral therapy (CBT) is effective and is one of the most common therapy provided to university students for prevention or early intervention of depression and anxiety. ${ }^{[27-29]}$ It is also important to note that CBT has been recommended as the therapy of choice for anxiety and depression. ${ }^{[30]}$ Further, CBT is commonly provided in groups as preventive interventions in schools. ${ }^{[31]}$

Therefore a literature review focusing on intervention studies for university students' based on cognitive behavioral group therapy (CBGT) to lower levels of psychological distress, primarily depressive and/or anxiety symptoms, was conducted. The review was mainly guided by the two following questions: How are the cognitive behavioral group therapies designed in terms of length and structure of therapy? What are the demographic characteristics of the student samples participating in the respective trials? Key-terms included psychological distress, depression, anxiety, cognitive behavioral group therapy, and university/college students. Research articles between 1999 and 2008 were searched in: ProQuest, PubMed and Chinal and the reference lists of relevant articles were chequed. Inclusion criteria were university or college students, 17 years of age and older, primary focus of the intervention were symptoms of depression with or without associated anxiety, cognitive behavioral group therapy was the major component of the respective therapy. Exclusion criteria were youth under the age of 17, disorders such as bipolar, post-partum depression and anxiety disorders (other than general anxiety), third-wave CBT and CBT provided mainly with other modalities than groups, such as individual therapy or therapy through the internet.

Six articles met the inclusion criteria and were included in the review. Four focused on students who were mild to moderately depressed and/or anxious and the main purpose of the therapies were prevention or early intervention. ${ }^{[32-35]}$ One study was directed at psychological distress in general ac- 
cording to the SCL-90 scale along with perceived stress. ${ }^{[36]}$ Another study was directed at depression, self-esteem and negative automatic thoughts. ${ }^{[37,38]}$

\subsection{Length and structure of therapy}

According to the literature review CBGT was mainly provided to students with mild to moderate stages of depression and associated distress. The therapy was most often brief and provided in groups of approximately 10 to $16 \mathrm{stu}-$ dents, typically meeting in six to eight consecutive weekly sessions that lasted for one to two hours. ${ }^{[34-38]}$ Two therapies lasted longer, one focusing on students with moderate depression which lasted for 11 weeks and the other lasted for 15 weeks for students with sub-clinical depression and anxiety. ${ }^{[32,33]}$ Two of the intervention studies added individual sessions to the group format ${ }^{[34,35]}$ and one of them also provided material on the internet and used e-mails to communicate with students. ${ }^{[35]}$ Further, the interventions were generally classroom-based and some compensated the students. ${ }^{[32,34-36]}$ All six studies reported a decrease in symptoms of depression after the CBGT was completed. Four of the studies measured co-occurring symptoms of anxiety which all reported a reduction of the symptoms post therapy. ${ }^{[32,34-36]}$

\subsection{Demographic characteristics of participants}

The samples in five of the six studies consisted of mixed groups of males and females, and one which consisted of females only. ${ }^{[37,38]}$ The age range of participants was mostly between 18-25 years but one study reported an age range from 17 to 60 years. ${ }^{[32,36,37]}$ Participants in four of the intervention studies were undergraduates only. ${ }^{[33-35,38]}$

\section{DESIGN OF THE PRELIMINARY INTERVEN- TION}

The aim of this phase of intervention design, according to van Meijel et al. is to draft the intervention based on theory and results of the literature review. ${ }^{[9]}$ The intervention described in this paper is regarded as an evidence-based nursing intervention targeting female university students who demonstrate symptoms of psychological distress with symptoms of depression and/or anxiety.

\subsection{Expert group}

To inform and advise on each step of this current intervention design and the writing of a manual, an expert group of nurses was formed, as recommended by van Meijel et al. ${ }^{[9]}$ Six nurses with an extended experience in being or working with university students, formed the expert panel. One member was a new graduate from university studies, another was currently a graduate student, while the others were either advanced practice psychiatric nurses working with cognitive behavioral therapy or nurse educators. The main role of the expert group was to provide feed-back and information related to the intervention design, the nature of students' mental health needs, intervention approach, number of sessions and educational and homework material.

Previously, an Icelandic cross-sectional internet study among university female students had found the majority of female students who experienced elevated psychological distress also exhibited mild to moderate levels of symptoms similar to other international findings. ${ }^{[6,39]}$ Therefore, and based on the results of the literature review, the expert group decided to develop a brief group intervention within the framework of CBT approach to target this group. As this was considered a homogenous group, including females only, it was decided to offer this current intervention in four sessions with a maximum of 8 participants in each group. Each session should last for 120 minutes and be provided for both undergraduate and graduate students aged 19-45 years of age from all university faculties. Further it was also decided to provide the intervention on campus in a class-room environment similar to other CBGT for university students. ${ }^{[32,35]}$ This was partly done to assist students in accommodating the intervention into their school schedules and to save time. Finally, it was decided that students should not be compensated.

\subsection{Intervention theory}

Based on the review of the literature it was decided to integrate cognitive behavioral therapy approach according to Beck $^{[40]}$ and the stress process model by Pearlin, Menaghan, Morton and Mullan ${ }^{[41]}$ in the intervention approach. The stress process model, as well as Beck's CBT maintain that individuals' appraisal of internal or external stressors strongly influences their emotional, behavioral and physical reactions, which may be constructive or not. ${ }^{[40,41]}$ The stress process model further explains how stress is evoked by different stressors or milestones which may be embedded in the lives of university students. The model proposes that the stress process is mediated through a person's self-concept, support and coping. Subsequently, psychological distress is more likely to occur if the sources of stress undermine the individual's personal resources or self-concept, including mastery and self-esteem. ${ }^{[41]}$ It is therefore of importance to protect or enhance the female students self-concept through interventions that increase social support and coping skills. To promote supportive interaction and connections among participants it was decided to provide sessions in small groups of peers and two facilitators. The main topics and sequence of the brief cognitive behavioral group therapy sessions were the following: 
(1) What is psychological distress

(2) How to deal with stress

(3) How to enhance self-esteem and sense of control

(4) Wrap up and setting goals

\subsection{Intervention delivery}

Two APPNs administered the face-to-face cognitive behavioral group therapy intervention. One of the APPNs was trained in cognitive behavioral therapy and the other was an assistant professor in psychiatric nursing. The intervention was carried out in three subgroups of five to eight women $(n=19)$ in the middle of the spring semester 2008. All sessions were held in a classroom at the School of Nursing that was designated to provide a therapeutic environment. Each session included two hours of therapy with a short refreshment break. A manual providing educational information and guidelines for homework assignments had been written beforehand and reviewed by the expert panel. Consequently all participants and the facilitators worked with the same written material for the purpose of increasing intervention fidelity. ${ }^{[8]}$ The group facilitators and participants were seen as co-workers who collaborated to provide the participants with information and skills to deal with stress and psychological distress. Active participation and engagement of students was encouraged. Students themselves brought to sessions examples from their own daily life which the group worked on, for instance, with thought records and behavioral activation schedules. Warmth, understanding and respect for individual experiences were valued. ${ }^{[42]}$ A more detailed description of the preliminary intervention has been described elsewhere. ${ }^{[8]}$

\section{VALIDATION OF THE PRELIMINARY IN- TERVENTION}

The aim of the validation phase was to evaluate the preliminary CBGT intervention to ameliorate psychological distress among Icelandic female university students and to gain students' views on their experience of undergoing therapy. Further, students' notions of the most and least helpful components of the therapy were explored. This input from participants was essential for the expert group when revising the intervention.

The validation of this current CBGT intervention, which has been described in more detail elsewhere, was conducted in two main steps. In the first step the effectiveness of the cognitive behavioral group therapy post intervention was evaluated with a quasi-experimental study $(\mathrm{n}=30)$ and in the second step the acceptability of the intervention was evaluated with semi-structured interviews and a qualitative content analysis $(\mathrm{n}=19){ }^{[8,10]}$

Published by Sciedu Press

\section{Results of the validation of the preliminay intervention}

The validation of the intervention, based on two previous studies, showed positive results. The quasi-experimental study showed that psychological distress decreased significantly in the intervention group $(n=19)$ compared to the control group $(\mathrm{n}=11)$ post therapy. ${ }^{[8]}$ This finding concurs with other more recent CBGT intervention studies which were also provided in four sessions for mildly depressed and/or anxious students. ${ }^{[43-45]}$ The major finding of the qualitative study was that the participants evaluated the brief CBGT intervention favorably and felt their mood improved. ${ }^{[10]}$ This finding is comparable to those from other qualitative studies that did not include students. ${ }^{[46,47]}$ Participants in this current intervention explained the beneficial outcomes in the combination of education, cognitive restructuring and group discussions. ${ }^{[10]}$ The results of the previous studies has led to revisions of the structure and content of preliminary intervention by the expert panel as displayed in nine categories in Table 1.

\section{Discussion}

\subsection{Revision of intervention structure}

As the participants in the qualitative study expressed a need for more time, than offered by four sessions, in order to ponder over the educational material, to practice the proposed skills and to engage in private conversation with the therapist it is recommended to add two sessions from 4 to 6 , and a booster session, to the program. ${ }^{[10]}$ This recommendation is in line with 4-6 sessions offered in studies conducted on the effectiveness of CBGT to ameliorate symptoms of depression and related distress among university students. ${ }^{[44,45,48]}$ Furthermore, it has been shown that web-based and computer delivered interventions can have a positive effect on depression and anxiety among university students. ${ }^{[49]}$ Therefore it is proposed that internet based learning should be part of future programs aimed at amelioration of mild distress. However, the face-to-face sessions as conducted in this current intervention, are suggested to be maintained and used for in-depth discussions and revisions of homework and educational material. This is supposed to meet the students demand for more in-depth discussions. Additionally, there should be scope for individual counselling sessions, as suggested by participants in the qualitative study. This would meet the students' need for discussion of confidential concerns they were reluctant to discuss in a group setting. ${ }^{[10]}$ This is similar to the cognitive behavioral group therapy by Seligman, Schulman and Tryon ${ }^{[35]}$ provided to university students. As it takes time to build trust in a therapeutic relationship, it is suggested that individual counselling session should be scheduled in the latter part of the program. 
Table 1. Revisions of the preliminary CBGT

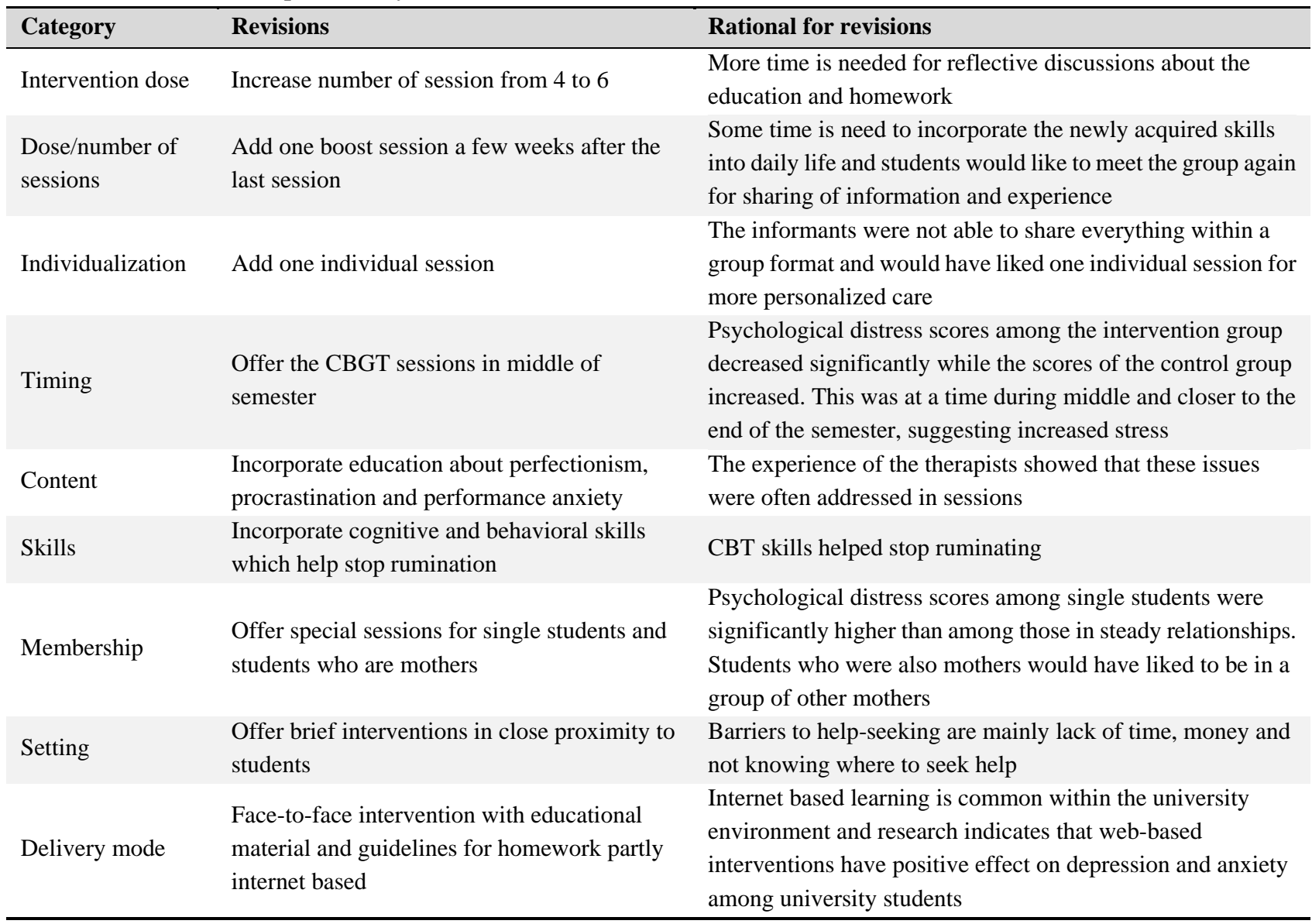

Participants, in the qualitative study, remarked that a group size of approximately six to eight members was optimal and therefore this intervention component is proposed to remain unchanged in future. ${ }^{[10]}$ This proposition concurs with CBGT intervention studies where 4-8 students were assigned to each CBT group. ${ }^{[48,50]}$ A special group for students that are mothers has also been suggested. ${ }^{[10]}$ As an Icelandic prevalence study showed that single students experience higher psychological distress levels than married and co-habiting students it is furthermore recommended that special groups for single students should be offered in future. ${ }^{[6]}$ The setting for an intervention is recommended to be similar to that of the present study as participants appreciated the surroundings and the comfortable atmosphere of the environment. It appears comparable to the one found in another study where APPNs were therapists. ${ }^{[51]}$ Finally, the participants felt that the intervention should be implemented shortly after they begin their university studies in order to proceed in a healthier state throughout their academic career. ${ }^{[10]}$ This reasoning is in line with research showing that psychological distress is highest among students in the first semester of university studies. ${ }^{[1]}$ Therefore special groups for students who are in the beginning phase of their university experience should be considered.

\subsection{Revisions of intervention content}

The APPNs facilitating the groups felt that participants expressed characteristics of perfectionism, procrastination and performance anxiety. Therefore, adding educational material especially related to these characteristics is advocated, especially as cognitive group approaches have been found to be helpful in decreasing the level of perfectionism and procrastination among participants. ${ }^{[52,53]}$ As the participants found that behavioral skills helped them stop ruminating, these skills should be emphasized in a revised intervention. ${ }^{[10]}$ The female students reported that by changing their inner self-dialogue they became more tolerant and accepting of their limitations. This finding concurs with studies showing that the practice of positive affirmations is a component of therapy for university female students. ${ }^{[37,38]}$ Therefore, enhancing the practice of this skill will be emphasized in the revised intervention.

Interestingly, the female students, in the qualitative study, described a new perspective amongst themselves which they 
explained as a feeling of increased understanding and compassion towards self and others. ${ }^{[10]}$ This is important to note, as practice of self- compassion has been found to increase the efficacy of cognitive reappraisal among depressed clients. ${ }^{[54]}$ Finally, as psychological distress is generally considered to be related to the transitional experience of young adulthood and university studies, further studies on psychological distress and the development of interventions for students should preferably be framed within framework of a transitional theory. ${ }^{[5]}$

\section{Conclusion}

A brief CBGT intervention designed and delivered by APPNs to a group of Icelandic female university students was effective to ameliorate psychological distress of mild to moderate degree. The brief intervention has been revised by the expert panel based on the results of the validation of the preliminary intervention. To further increase effectiveness, acceptability and validity of the intervention some parts have been suggested to revise in future intervention studies.

\section{Conflicts of InTEREST Disclosure}

The authors declare that there is no conflict of interest.

\section{REFERENCES}

[1] Bewick B, Koutsopoulou G, Miles J, et al. Changes in undergraduate students' psychological well-being as they progress through university. Studies in Higher Education. 2010; 35(6): 633-45. https : //doi.org/10.1080/03075070903216643

[2] Stallman HM. Psychological distress in university students: A comparison with general population data. Australian Psychologist. 2010; 45(4): 249-57. https://doi.org/10.1080/00050067.2 010.482109

[3] Bayram N, Bilgel N. The prevalence and socio-demographic correlations of depression, anxiety and stress among a group of university students. Social psychiatry and psychiatric epidemiology. 2008; 43(8): 667-72. PMid:18398558 https://doi.org/10.1007/s0 0127-008-0345-x

[4] Mahmoud JSR, Staten RT, Hall LA, et al. The Relationship among Young Adult College Students' Depression, Anxiety, Stress, Demographics, Life Satisfaction, and Coping Styles. Issues in Mental Health Nursing. 2012; 33(3): 149-56. https://doi .org/10.310 9/01612840.2011.632708

[5] Conley CS, Kirsch AC, Dickson DA, et al. Negotiating the Transition to College. Emerging Adulthood. 2014; 2(3): 195-210. https: //doi.org/10.1177/2167696814521808

[6] Bernhardsdóttir J, Vilhjálmsson R. Psychological distress among university female students and their need for mental health services. Journal of Psychiatric and Mental Health Nursing. 2013; 20(8): 6728. https://doi.org/10.1111/jpm. 12002

[7] Eisenberg D, Hunt J, Speer N, et al. Mental Health Service Utilization Among College Students in the United States. The Journal of Nervous and Mental Disease. 2011; 199(5).

[8] Bernhardsdottir J, Vilhjalmsson R, Champion JD. Evaluation of a brief Cognitive Behavioral Group Therapy for Psychological Distress among Female Icelandic University Students. Issues in Mental Health Nursing. 2013; 34(7): 497-504. https://doi.org/10.3109/01 612840.2013 .773473

[9] van Meijel B, Gamel C, van Swieten-Duijfjes B, et al. The development of evidence-based nursing interventions: methodological considerations. Journal of Advanced Nursing. 2004; 48(1): 84-92. https://doi.org/10.1111/j.1365-2648.2004.03171.x

[10] Bernhardsdottir J, Champion JD, Skärsäter I. The experience of participation in a brief cognitive behavioural group therapy for psychologically distressed female university students. Journal of Psychiatric and Mental Health Nursing. 2014; 21(8): 679-86. https: //doi.org/10.1111/jpm.12106

Published by Sciedu Press
[11] Cuijpers P, Smit F. Subthreshold depression as a risk indicator for major depressive disorder: a systematic review of prospective studies. Acta Psychiatrica Scandinavica. 2004; 109(5): 325-31. https://doi.org/10.1111/j.1600-0447.2004.00301.x

[12] Mirowsky R, Ross CE. Social Causes of Psychological Distress. Hawthorne, NY: Aldine de Gruyter; 2003.

[13] Beiter R, Nash R, McCrady M, et al. The prevalence and correlates of depression, anxiety, and stress in a sample of college students. Journal of Affective Disorders. 2014; 173: 90-6. https: //doi.org/10.1016/j.jad.2014.10.054

[14] Papier K, Ahmed F, Lee P, et al. Stress and dietary behaviour among first-year university students in Australia: Sex differences. Nutrition. 2015; 31(2): 324-30. https://doi.org/10.1016/j.nut. 2014 .08 .004

[15] Pozos-Radillo BE, Preciado-Serrano MdL, Acosta-Fernández M, et al. Academic stress as a predictor of chronic stress in university students. Psicología Educativa. 2014; 20(1): 47-52. https: //doi.org/10.1016/j.pse.2014.05.006

[16] Brandy JM, Penckofer S, Solari-Twadell PA, et al. Factors predictive of depression in first-year college students. Journal of Psychosocial Nursing and Mental Health services. 2015; 53(2): 38.

[17] Brzezinski S, Millar R, Tracey A. What do tertiary level students in the U.S.A. and Northern Ireland (UK) worry about? An exploratory study. British Journal of Guidance \& Counselling. 2017; 1-16 p. https://doi.org/10.1080/03069885.2017.1286634

[18] Coiro MJ, Bettis AH, Compas BE. College students coping with interpersonal stress: Examining a control-based model of coping. Journal of American College Health. 2017; 65(3): 177-86. https://doi.org/10.1080/07448481.2016.1266641

[19] Andrews B, Wilding JM. The relation of depression and anxiety to life-stress and achievement in students. British Journal of Psychology. 2004; 95(4): 509-21. PMid:15527535 https ://doi.org/10. 134 $8 / 0007126042369802$

[20] Adams TB, Wharton CM, Quilter L, et al. The Association Between Mental Health and Acute Infectious Illness Among a National Sample of 18- to 24-Year-Old College Students. Journal of American College Health. 2008; 56(6): 657-64.

[21] Geisner IM, Mallett K, Kilmer JR. An Examination of Depressive Symptoms and Drinking Patterns in First Year College Students. Issues in Mental Health Nursing. 2012; 33(5): 280-7. https: //doi.org/10.3109/01612840.2011.653036 
[22] Kenney BA, Holahan CJ. Depressive Symptoms and Cigarette Smoking in a College Sample. Journal of American College Health. 2008; 56(4): 409.

[23] Schofield MJ, O'Halloran P, McLean SA, et al. Depressive Symptoms Among Australian University Students: Who Is at Risk? Australian Psychologist. 2016; 51(2): 135-44. https ://doi.org/10.1111/ ap. 12129

[24] Lovell GP, Nash K, Sharman R, et al. A cross-sectional investigation of depressive, anxiety, and stress symptoms and healthbehavior participation in Australian university students. Nursing \& Health Sciences. 2015; 17(1): 134-42. PMid:24799077 https: //doi.org/10.1111/nhs.12147

[25] Tembo C, Burns S, Kalembo F. The association between levels of alcohol consumption and mental health problems and academic performance among young university students. PLOS ONE. 2017; 12(6): 1-14. https://doi.org/10.1371/journal.pone.0178142

[26] Hysenbegasi A, Hass SL, Rowland CR. The impact of depression on the academic productivity of university students. Journal of Mental Health Policy and Economics. 2005; 8(3): 145-51.

[27] Buchanan JL. Prevention of Depression in the College Student Population: A Review of the Literature. Archives of Psychiatric Nursing. 2012; 26(1): 21-42. https ://doi .org/10.1016/j . apnu. 2011. 03.003

[28] Reavley N, Jorm AF. Prevention and early intervention to improve mental health in higher education students: a review. Early Intervention in Psychiatry. 2010; 4(2): 132-42. PMid:20536969 https://doi.org/10.1111/j.1751-7893.2010.00167.x

[29] Pan JY, Ng P, Young DKW, et al. Effectiveness of Cognitive Behavioral Group Intervention on Acculturation. Research on Social Work Practice. 2017; 27(1): 68-79. https ://doi.org/10.1177/1049 731516646857

[30] Tolin DF. Is cognitive-behavioral therapy more effective than other therapies?: A meta-analytic review. Clinical Psychology Review. 2010; 30(6): 710-20. https://doi.org/10.1016/j.cpr.2010 .05 .003

[31] Macklem GL. Evidence-based school mental health services. Affect education, emotion regulation training, and cognitive behavioral therapy. New York, NY: Springer; 2011.

[32] Brown SL, Schiraldi GR. Reducing Subclinical Symptoms of Anxiety and Depression: A Comparison of Two College Courses. American Journal of Health Education. 2004; 35(3): 158-64. https : //doi.org/10.1080/19325037.2004.10603632

[33] Hamamci Z. Integrating psychodrama and cognitive behavioral therapy to treat moderate depression. The Arts in Psychotherapy. 2006; 33(3): 199-207. https://doi.org/10.1016/j.aip.2006.02. 001

[34] Seligman MEP, Schulman P, DeRubeis RJ, et al. The prevention of depression and anxiety. Prevention \& Treatment. 1999; 2(1) https://doi.org/10.1037/1522-3736.2.1.28a

[35] Seligman MEP, Schulman P, Tryon AM. Group prevention of depression and anxiety symptoms. Behaviour Research and Therapy. 2007; 45(6): 1111-26. https://doi.org/10.1016/j.brat.2006.09 .010

[36] Deckro GR, Ballinger KM, Hoyt M, et al. The Evaluation of a Mind/Body Intervention to Reduce Psychological Distress and Perceived Stress in College Students. Journal of American College Health. 2002; 50(6): 281.

[37] Peden AR, Hall LA, Rayens MK, et al. Reducing negative thinking and depressive symptoms in college women. Journal of Nursing Scholarship. 2000; 32(2): 145-51. https ://doi.org/10.1111/j . $1547-5069.2000 .00145 . x$
[38] Peden AR, Rayens MK, Hall LA, et al. Preventing Depression in High-Risk College Women: A Report of an 18-month Follow-up. Journal of American College Health. 2001; 49(6): 299.

[39] Cvetkovski S, Reavley NJ, Jorm AF. The prevalence and correlates of psychological distress in Australian tertiary students compared to their community peers. Australian and New Zealand Journal of Psychiatry. 2012; 46(5): 457-67. PMid:22535294 https : //doi.org/10.1177/0004867411435290

[40] Beck AT, Rush AJ, Shaw BF, et al. Cognitive therapy of depression. New York, NY: The Guilford Press; 1979.

[41] Pearlin LI, Menaghan EG, Morton AL, et al. The Stress Process. Journal of Health and Social Behavior. 1981; 22(4): 337-56. https : //doi.org/10.2307/2136676

[42] Free ML. Cognitive therapy in groups. Guidelines and resources for practice (2ed.). West Sussex, England: John Wiley \& Sons, Ltd; 2007.

[43] Du X, Mao Y, Ran Q, et al. Short-term group cognitive behavior therapy contributes to recovery from mild depression: Evidence from functional and structural MRI. Psychiatry Research: Neuroimaging. 2016; 251: 53-9. https://doi.org/10.1016/j.pscychresns . 2016.04 .010

[44] Mokrue K, Acri M. Feasibility and Effectiveness of a Brief Cognitive Behavioral Skills Group on an Ethnically Diverse Campus. Journal of College Student Psychotherapy. 2013; 27(3): 254-69. https ://doi.org/10.1080/87568225.2013.766114

[45] Buchanan JL. Translating Research Into Practice: Targeting Negative Thinking as a Modifiable Risk Factor for Depression Prevention in the College Student Population. Archives of Psychiatric Nursing. 2013; 27(3): 130-6. https ://doi.org/10.1016/j .apnu. 2013. 02.002

[46] Cramer H, Salisbury C, Conrad J, et al. Group cognitive behavioural therapy for women with depression: pilot and feasibility study for a randomised controlled trial using mixed methods. BMC Psychiatry. 2011; 11(1): 82-92. https://doi.org/10.1186/1471-244X-1 $1-82$

[47] Wong FKD. Cognitive Behavioral Group Treatment for Chinese People with Depressive Symptoms in Hong Kong: Participants' Perspectives. International Journal of Group Psychotherapy. 2011; 61(3): 438-59. https://doi.org/10.1521/ijgp.2011.61.3.438

[48] Rohde P, Stice E, Shaw H, et al. Cognitive-behavioral group depression prevention compared to bibliotherapy and brochure control: Nonsignificant effects in pilot effectiveness trial with college students. Behaviour Research and Therapy. 2014; 55: 48-53. https://doi.org/10.1016/j.brat.2014.02.003

[49] Davies EB, Morriss R, Glazebrook C. Computer-Delivered and WebBased Interventions to Improve Depression, Anxiety, and Psychological Well-Being of University Students: A Systematic Review and Meta-Analysis. Journal of Medical Internet Research. 2014; 16(5): e130. https://doi.org/10.2196/jmir.3142

[50] Vázquez FL, Torres A, Blanco V, et al. Comparison of relaxation training with a cognitive-behavioural intervention for indicated prevention of depression in university students: A randomized controlled trial. Journal of Psychiatric Research. 2012; 46(11): 1456-63. https://doi.org/10.1016/j.jpsychires.2012.08.007

[51] Parrish E, Peden A, Staten RT, et al. Advanced Practice Psychiatric Nurses' Outcomes of Care: A Pilot Study. Issues in Mental Health Nursing. 2013; 34(8): 587-94. https ://doi.org/10.3109/0161 2840.2013 .789944

[52] Handley AK, Egan SJ, Kane RT, et al. A randomised controlled trial of group cognitive behavioural therapy for perfectionism. Behaviour Research and Therapy. 2015; 68: 37-47. https ://doi .org/10.1 $016 /$ j.brat .2015 .02 .006 
[53] Uzun Ozer B, Demir A, Ferrari JR. Reducing Academic Procrastination Through a Group Treatment Program: A Pilot Study. Journal of Rational-Emotive \& Cognitive-Behavior Therapy. 2013; 31(3): 127-35. https://doi.org/10.1007/s10942-013-0165-0
[54] Diedrich A, Hofmann SG, Cuijpers P, et al. Self-compassion enhances the efficacy of explicit cognitive reappraisal as an emotion regulation strategy in individuals with major depressive disorder. Behaviour Research and Therapy. 2016; 82: 1-10. https: //doi.org/10.1016/j.brat.2016.04.003 